\title{
Long-term outcome after traumatic anterior dislocation of the hip
}

\author{
Johannes Dominik Bastian • M. Turina • \\ K. A. Siebenrock • M. J. B. Keel
}

Received: 7 November 2010/Published online: 20 March 2011

(c) Springer-Verlag 2011

\begin{abstract}
Introduction Traumatic anterior dislocation of the hip joint is rare. Additional injuries to the hip due to dislocation are even more infrequent. Outcome is limited by osteoarthritic joint degeneration or the occurrence of avascular necrosis of the femoral head.

Method Anterior hip dislocation occurred in ten of 100 patients with traumatic hip dislocations ( 8 men, mean age: 43 , 22-62years) at two major trauma centres, between January 2001 and December 2008. Four patients had impaction fractures of the femoral head and three patients had fractures of the anterior acetabular wall. One patient presented with an open dislocation. In three of the ten patients surgical treatment was necessary.

Results Nine patients were evaluated retrospectively at a follow-up of $4.8 \pm 2.3$ years (mean $\pm \mathrm{SD}$ ). The mean scores were $88 \pm 19$ (Harris Hip-Score), $15 \pm 23$ (WOMAC-Score), level 6 (UCLA-Score). Four cases presented with only fair clinical or radiological results according to Epstein. AVN with collapse of the femoral head was observed in one.

Conclusion Traumatic anterior hip dislocations presented in six of the ten cases with additional injuries to the hip. Surgical treatment in cases with deep impaction fractures of the femoral head or with large fragments of the acetabulum may improve the outcome.
\end{abstract}

J. D. Bastian $(\bowtie) \cdot$ K. A. Siebenrock · M. J. B. Keel Department of Orthopaedic Surgery, University of Bern, Inselspital, Freiburgstrasse 3, 3010 Bern, Switzerland e-mail: johannesbastian@gmx.de

M. Turina

Division of Trauma Surgery, Department of Surgery, University of Zürich Hospital, Rämistrasse 100, 8091 Zurich, Switzerland
Keywords Anterior hip dislocation · Traumatic . Fracture - Osteochondral defect

\section{Introduction}

Traumatic hip dislocations are usually observed following high-energy trauma-mostly caused by traffic accidents [1-3], but also seen in professional athletes [4]. Hip dislocations are classified into central, posterior and anterior types, whereas the latter are further subdivided into inferior (obturator) and superior (pubic) types [5]. Anterior hip dislocation is a rare injury, with a reported frequency ranging between $7-13 \%[1,6]$ of all hip dislocations. Injuries associated with anterior hip dislocation such as impaction fractures of the femoral head have reported frequencies ranging from 15 to $35 \%$ [7-9], whereas fractures of the acetabulum were rarer, occurring in only $4 \%$ [9] of cases. The purpose of this study was to revisit this rare joint dislocation, to describe the pattern of injury and long-term outcome in a retrospective series of adult patients treated at two trauma centres.

\section{Patients and methods}

Between January 2001 and December 2008, a total of 60 traumatic dislocations of the hip (7/60 anterior, 53/60 posterior) were admitted to a level one trauma centre. Between January 2004 and December 2008, a total of 40 traumatic dislocations of the hip (3/40 anterior, 37/40 posterior) were admitted to a second level one trauma centre.

Closed reduction was performed with the patient in the supine position under general anaesthesia in all cases. 
Traction was applied in the line of the deformity, and a combination of rotary movements and gentle pressure on the flexed knee were used to reduce the femoral head into the acetabulum. After successful closed reduction, computed tomography of the hip joint was performed in all cases in order to detect additional injuries. In terms of additional hip injuries, the indication for surgery was impaction fractures deeper than $4 \mathrm{~mm}$, which are at an increased risk of developing post-traumatic osteoarthritis [10]. As is the case with posterior acetabular fracture-dislocations, acetabular fractures involving more than $25 \%$ of the acetabulum might compromise hip stability [11] and were treated operatively using an iliofemoral approach (modified Smith-Petersen approach).

The course and requirements of the postoperative rehabilitation depended on the additional injuries to the hip and/or additional orthopaedic injuries (e.g. partial weight bearing in the case of fractures of the tibial plateau or the femur or transfer to a wheel chair in cases of bilateral fractures of the medial malleoli). In cases undergoing nonoperative treatment, full weight bearing was allowed with crutch assistance for 2 weeks. In addition, passive extension was not allowed and active hip flexion was limited to $90^{\circ}$ for this period to reduce stress on the afflicted anterior joint capsule and to lower the risk of hip flexor tendinitis, respectively $[12,13]$.

In cases undergoing surgical treatment, partial weight bearing of approximately $15 \mathrm{~kg}$ of the injured lower extremity and no more than $90^{\circ}$ of flexion with no extension for 6 weeks were required except in one case treated with osteochondral transplantation. In this particular case, the limitations of the aftercare were partial weight bearing of approximately $15 \mathrm{~kg}$ of the left lower extremity for 3 months and no more than $60^{\circ}$ of flexion of the left hip for 6 weeks.

The functional status of the injured hip joint was assessed using the Harris Hip Score [14, 15], the WOMAC Score [16] and the patients' activity status with the UCLA Score [17]. The occurrence of osteoarthritis (OA), heterotopic ossifications (HO) or avascular femoral head necrosis (AVN) was evaluated according to Tönnis [18], Brooker [19] and Ficat [20] classifications respectively. Overall evaluation of the clinical and radiological results was performed using the ranking criteria by Epstein [7]. Accordingly, the clinical results were graded as "excellent", "good", "fair" or "poor" and the radiological results were graded as "excellent" (normal), "good" (minimum changes), "fair" (moderate changes) or "poor" (severe changes).

$P$ values are not provided as the statistical analysis used was descriptive. The assessments of the patients were undertaken by the first author (JDB).

\section{Results}

Traumatic anterior hip dislocation occurred in ten of 100 patients admitted for traumatic hip dislocation at two institutions ( 8 men, mean age: $43,22-62$ years). In seven of ten cases dislocations were anteroinferior and three of ten were anterosuperior (Table 1). The mean Glasgow Coma Scale (GCS) was $12.8 \pm 4.4$ and the mean Injury Severity Score (ISS) [21] was $16.6 \pm 11.6$. In eight of ten cases (case 1, 2, 4-6, 8-10), patients experienced a high-energy trauma, with additional orthopaedic and/or non-orthopaedic injuries. In two of ten cases the patients sustained no further injuries to the body and were initially transferred to the nearest hospital (case 3, 7). For all patients, the mean hospital stay was $12.3 \pm 8.6$ days (Table 2).

Four patients had no additional injuries associated with the dislocation (cases 2, 4, 5, 8). Four patients presented with impaction fractures of the femoral head (cases 6, 7, 9, 10) and three patients had fractures of the anterior acetabular wall (cases 1, 3,7), which in one was an open dislocation (case 1). Seven of ten patients were treated nonoperatively (cases 2-6, 8, 10): Four patients showed simple dislocations without additional injuries to the hip (cases 2, $4,5,8)$, two patients had femoral head impaction fractures $<4 \mathrm{~mm}$ depth (cases 6,10 ) and in one patient with a fracture of the anterior acetabular wall the fragment was too small to be fixed (case 3 ).

Three of ten patients underwent surgery (cases $1,7,9$ ) to treat the additional injuries caused by the traumatic dislocation (Table 2). Surgical hip dislocation with osteochondral transplantation (OCT) [22] was necessary in one patient due to a large-sized defect in the femoral head due to an impaction fracture ( $>4 \mathrm{~mm}$ depth) (case 9$)$. In two cases, anterior wall fragments (involving $>25 \%$ of the acetabulum) were either fixed by screws or by plate osteosynthesis to prevent consecutive hip instability (case 1; case 7, Fig. 1).

Nine of ten patients were assessed clinically and radiologically at a follow-up of $4.8 \pm 2.3$ years (mean $\pm \mathrm{SD}$ ). One patient was lost to follow-up due to relocation to another country. The individual results of each case are presented in Table 3 for the clinical and in Table 4 for the radiological parameters. The overall results documented at the last follow-up were: mean Harris Hip Score: $88 \pm 19$, WOMAC Score: $15 \pm 23$, mean UCLA Score of 6 . Four, two and three patients had an excellent, good, fair clinical result, respectively, according to Epstein criteria.

In the radiological assessment, in three patients (cases 1, 3 ,6) osteoarthritic changes were observed (grade I: 1, grade II: 2) and four patients (cases 1, 3, 7, 9) had 
Table 1 Overview of patient collective: patients' demographics, trauma mechanism, Glasgow Coma Scale (GCS), Injury Severity Score (ISS), direction of dislocation, associated injuries

\begin{tabular}{|c|c|c|c|c|c|c|c|}
\hline Case & Age & Sex & Accident & GCS & ISS & Direction & Associated injuries \\
\hline 1 & 48 & M & Motorbike & 3 & 10 & Superior (open) & $\begin{array}{l}\text { "Open-book" injury of the pelvic ring, left sided femoral } \\
\text { fracture and a traumatic amputation of the left lower leg }\end{array}$ \\
\hline 2 & 55 & M & At work & 15 & 9 & Inferior & Posterior elbow dislocation \\
\hline 3 & 22 & M & Bicycle & 15 & 9 & Superior & None \\
\hline 4 & 32 & $\mathrm{~F}$ & Car & 15 & 19 & Inferior & $\begin{array}{l}\text { Fractures of the right lateral malleolus and the nasal } \\
\text { septum, bilateral pulmonal contusion and a lacerated } \\
\text { wound of the upper lip }\end{array}$ \\
\hline 5 & 29 & $\mathrm{M}$ & Car & 13 & 10 & Inferior & $\begin{array}{l}\text { Craniocerebral injury, chest trauma with pulmonal } \\
\text { contusion, open fracture of the left patella, rupture of the } \\
\text { anterior and posterior cruciate ligament and bilateral } \\
\text { fractures of the medial malleoli }\end{array}$ \\
\hline 6 & 62 & $\mathrm{~F}$ & Pedestrian & 15 & 14 & Inferior & $\begin{array}{l}\text { Fractures of the left superior pubic rami, the } 4 \text { th lumbar } \\
\text { vertebral body, the transverse processus, cutaneous } \\
\text { lacerations on the cheek and abrasions on the back }\end{array}$ \\
\hline 7 & 35 & M & At work & 15 & 9 & Superior & None \\
\hline 8 & 55 & M & Fall & 6 & 34 & Inferior & $\begin{array}{l}\text { Craniocerebral injury (GCS 6), blunt chest trauma with } \\
\text { pulmonal contusions, serial rib fractures (C2-10), } \\
\text { fractures of the left clavicle, 3rd lumbar vertebral body }\end{array}$ \\
\hline 9 & 48 & M & Motorbike & 15 & 11 & Inferior & $\begin{array}{l}\text { Right sided proximal tibia plateau fracture, soft tissue } \\
\text { avulsion at the right lower leg }\end{array}$ \\
\hline 10 & 39 & $\mathrm{M}$ & Car & 14 & 41 & Inferior & $\begin{array}{l}\text { Craniocerebral injury (GCS 14), chest trauma with bilatera } \\
\text { pulmonal contusion, rib fractures, bilateral } \\
\text { haematothorax, blunt abdominal trauma with splenic } \\
\text { laceration, fractures of the 3rd thoracic vertebral body }\end{array}$ \\
\hline
\end{tabular}

Table 2 Additional injuries: patients' additional hip joint injuries, therapy, duration of hospital stay (in days)

\begin{tabular}{|c|c|c|c|c|}
\hline Case & Femoral head & Acetabulum & Therapy & Hospital stay (days) \\
\hline 1 & - & Anterior wall fracture & Osteosynthesis acetabulum & 19 \\
\hline 2 & - & - & Closed reduction & 7 \\
\hline 3 & - & Anterior wall fracture & Closed reduction & 3 \\
\hline 4 & - & - & Closed reduction & 14 \\
\hline 5 & - & - & Closed reduction & 16 \\
\hline 6 & Impaction fracture & - & Closed reduction & 6 \\
\hline 7 & Impaction fracture & Anterior wall fracture & Osteosynthesis acetabulum & 5 \\
\hline 8 & - & - & Closed reduction & 32 \\
\hline 9 & Impaction fracture & - & Osteochondral transplantation & 9 \\
\hline 10 & Impaction fracture & - & Closed reduction & 12 \\
\hline
\end{tabular}

heterotopic ossifications (HO) during follow up (class I: 1, class II: 2, class III: 1). In three patients $\mathrm{HO}$ occurred at the anterolateral aspect of the hip, close to the site of the acetabular fracture within one year of the injury, and in one patient (case 9) at the anterior aspect of the capsule and cranial to the tip of the greater trochanter. Enucleation of these HOs was performed in two patients (cases 3, 7). AVN with collapse of the femoral head was observed in one patient (case 6), but at the last follow up, total joint replacement was not required. At the latest follow up, five, one and three patients were documented as showing excellent, good and fair results, respectively, according to Epstein criteria. In patients treated operatively, no perioperative complications were observed. No patient suffered from repeat dislocation during the period of follow-up.

\section{Discussion}

Due to the infrequency of anterior traumatic hip dislocations in comparison with posterior dislocations, details concerning anterior hip dislocations and associated injuries 
Fig. 1 a Anteroposterior radiograph of the pelvis: anterosuperior dislocation of the left hip with fracture of the anterior acetabular wall (case 7). b CT scans (sagittal) showing a large and displaced fracture fragment of the anterior acetabular wall (white arrow) and a slight $(<4 \mathrm{~mm})$ impaction of the femoral head (dotted line, black arrow). c Anteroposterior radiograph of the pelvis: postoperative radiological control after osteosynthesis of the anterior acetabular wall using screws. d Anteroposterior radiograph of the pelvis: excellent radiological outcome at the latest follow up after screw fixation of the acetabular wall fracture, partial hardware removal and enucleation of HOs
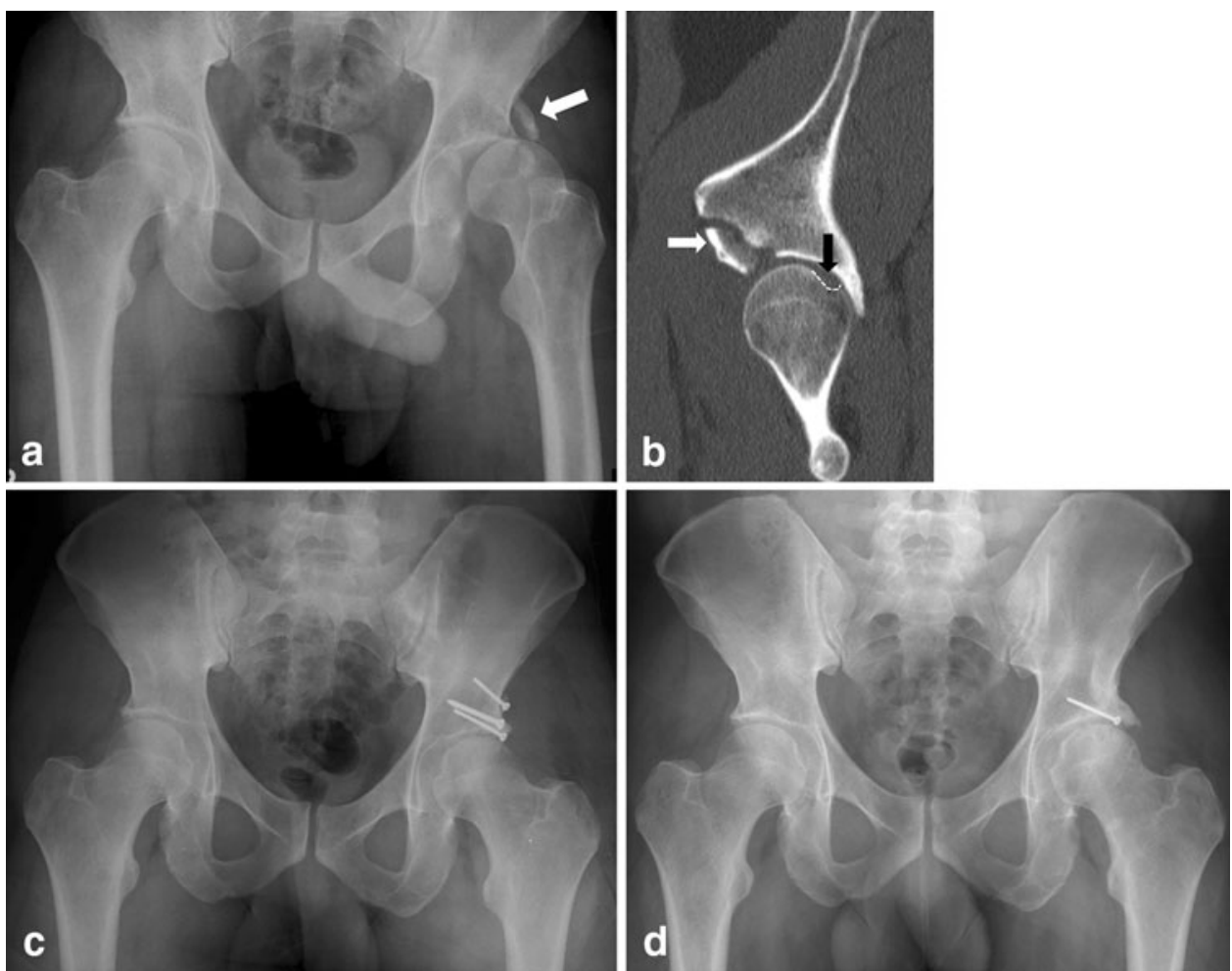

Table 3 Outcome Scores: Clinical outcomes assessed using the Harris Hip- (HHS), Womac-, UCLA activity-Scores, overall evaluation by the Epstein criteria at the latest follow up (FU) in years

\begin{tabular}{lrrcll}
\hline Case & HHS & WOMAC & UCLA & Epstein & FU \\
\hline 1 & 43 & 70 & 2 & Fair & 8.3 \\
2 & - & - & - & - & 0.1 \\
3 & 93 & 7 & 9 & Good & 7.1 \\
4 & 96 & 22 & 5 & Excellent & 6.4 \\
5 & 100 & 0 & 8 & Excellent & 4.8 \\
6 & 96 & 0 & 6 & Fair & 5.4 \\
7 & 72 & 21 & 10 & Fair & 3.5 \\
8 & 100 & 0 & 9 & Excellent & 3.3 \\
9 & 100 & 1 & 6 & Good & 2.1 \\
10 & 95 & 13 & 4 & Excellent & 1.8 \\
\hline
\end{tabular}

as well as treatment recommendations (non-operatively vs. operatively) are scarce. In our investigation, patients without any additional injuries to the hip were treated nonoperatively and generally showed excellent clinical and radiological results. Associated hip injuries complicating anterior hip dislocations are the occurrence of femoral head impaction fractures or fractures of the acetabulum at risk for post-traumatic hip osteoarthritis.

At the time of the anterior hip dislocation, the femoral head may be compressed against the anterior acetabular
Table 4 Radiologic assessment: radiological occurrence of osteoarthritis (OA), avascular necrosis (AVN) or heterotopic ossifications (HO), overall evaluation by the Epstein criteria at the latest follow up $(\mathrm{FU})$ in years

\begin{tabular}{llllll}
\hline Case & OA grade & AVN grade & HO grade & Epstein grade & FU \\
\hline 1 & 2 & 0 & 1 & Fair & 8.3 \\
2 & - & - & - & - & 0.1 \\
3 & 2 & 0 & 3 & Fair & 7.1 \\
4 & 0 & 0 & 0 & Excellent & 6.4 \\
5 & 0 & 0 & 0 & Excellent & 4.8 \\
6 & 1 & 3 & 0 & Fair & 5.4 \\
7 & 0 & 0 & 2 & Excellent & 2.7 \\
8 & 0 & 0 & 0 & Excellent & 3.3 \\
9 & 0 & 0 & 2 & Good & 2.1 \\
10 & 0 & 0 & 0 & Excellent & 1.8 \\
\hline
\end{tabular}

rim leading to impaction defects within the femoral head or avulsion/fracture of the anterior acetabular rim/wall. Impaction defects have been observed at variable frequencies ranging from 15 to $35 \%$ [7-9] and were associated with an increased incidence of post-traumatic osteoarthritis of the hip-from $23 \%$ overall to $88 \%$ when additional head impression fractures were present [7]. Severe osteoarthritic changes and poor clinical results have been reported, especially in patients with impaction fractures deeper than $4 \mathrm{~mm}$ [10]. Based on these findings, three 
patients (cases $6,7,10)$ with superficial ( $<4 \mathrm{~mm}$ depth) impaction fractures were treated non-operatively in our series, with excellent radiological outcome being obtained in two cases, whereas a fair outcome was achieved in one. The latter result was most probably related to the occurrence of AVN rather than to the occurrence of post-traumatic osteoarthritis. We observed AVN only in one case, which is in accordance with results found in the literature where the incidence of AVN after traumatic anterior hip dislocation was reported to be about $9 \%$ [1]. In one patient (case 9) a large defect of $10 \times 20 \mathrm{~mm}$ area and 5-mm depth was found in postreductional CT scans. In this case, surgical reconstruction with osteochondral transplantation involving the harvesting of an osteochondral autograft from the head-neck junction and transfer of the graft into the main defect in the femoral head was performed. This technique achieved good clinical and radiological results according to the Epstein criteria at 2 years and prevented early joint degeneration [22]. Although osteochondral transplantation is a well-described technique for the treatment of osteochondral defects in joints [23-26], the treatment of osteochondral defects in the hip joint has not been extensively described in the literature. Based on our results in this particular case, we recommend this technique as a salvage procedure for femoral head impaction fractures also after posterior hip dislocation and we confirm nonoperative treatment recommendations in cases of superficial femoral head impaction defects.

Little has been reported about the occurrence of acetabular fractures in combination with anterior hip dislocation [27]. Recommendations on the appropriate treatment of these fractures (non-operative versus operative) are scarce [3]. However, traumatic posterior hip dislocations are associated with fractures of the acetabulum in 46-70\% of cases [1, 5, 6, 28]. Regarding these cases, Vailas et al. stated that acetabular fracture fragments involving less than $25 \%$ of the acetabulum do not affect hip stability and might be treated non-operatively [11]. In our series, three of ten cases showed additional fractures of the acetabulum (Table 2, cases 1, 3, 7). In one patient (case 3) a small avulsion of the anterior acetabular rim was treated nonoperatively as the hip joint was stable. The patient showed good clinical results although early signs of joint degeneration could be seen on the radiograph at the long term. In two patients, surgical treatment for reduction and fixation of acetabular fracture fragments compromising hip stability yielded satisfying results. No patient with associated acetabular fracture suffered from repeat dislocation or hip instability during the period of follow-up. A further implication of traumatic anterior hip dislocation might be the occurrence of heterotopic ossifications since muscle injuries and haematoma have been identified as main risk factors [7]. In our series, HOs were frequently observed within the first year after trauma in four of nine cases. Enucleation of heterotopic ossifications was necessary in two of four cases. However, the remaining $50 \%$ had no adverse effects such as anterior hip impingement, limited range of motion or weakening of the abductor muscles, although $\mathrm{HO}$ was still present at the tip of the greater trochanter.

The strength of this study is the presentation of anterior hip dislocation with special focus on the additional injuries to the hip during long-term follow-up period, although the low number of cases may somewhat limit its value. The low frequency of occurrence of the described injuries restricts further clinical research, so that orthopaedic surgeons are reliant on sporadic reports to gather information on this rare injury. A further limitation might be that MRI scans for the detection of any intra-articular hip joint pathologies such as labral or chondral lesions may not have been performed. This may be the result of a lack of distinct recommendations concerning the use of MRI after anterior traumatic hip dislocation as well as the deficit in the amount of general information on chondral lesions or labrum injuries available in the literature [2, 4, 29]. However, in the acute trauma setting in the present study, conventional X-rays and CT scans were preformed after reduction to detect injuries requiring subsequent treatment. In the post-injury period, patients are re-evaluated 6 weeks after trauma in the outpatient clinic. In cases where patients complain of deep anterior groin pain, popping or locking or report a loss of motion or experience intractable pain after injury, we recommend the performance of MRI scans to detect intraarticular free fragments, labral tears or extended cartilage damage.

\section{Conclusion}

Traumatic anterior hip dislocations are rare. In such cases, additional injuries to the hip were frequently observed and resulted in an inferior clinical and radiological outcome. However, non-operative treatment of femoral head defects of less than 4-mm depth as well as surgical hip dislocation for osteochondral transplantation as a salvage procedure in defects of more than 4-mm depth allowed maintenance of the hip in the midterm. Occurrence of post-traumatic osteoarthritis was mainly related to additional acetabular fractures. Fractures involving the weight bearing-area and/or resulting in hip instability were treated with open reduction and internal fixation. In case of persistent hip pain following non-operative treatment after traumatic anterior hip dislocation MRI scans should be considered to allow detection of any intraarticular hip joint pathologies such as free fragments, labral or chondral lesions. 
Acknowledgments We thank Dr Debra Bickes-Kelleher for the linguistic help in the preparation of this manuscript.

Conflict of interest The authors declare that they have no conflict of interest.

\section{References}

1. Brav EA, Miller JA, Bouzard WC (1963) Traumatic Dislocation of the Cervical Spine Army experience and results. J Trauma 3:569-582

2. Dreinhofer KE, Schwarzkopf SR, Haas NP, Tscherne H (1994) Isolated traumatic dislocation of the hip. Long-term results in 50 patients. J Bone Joint Surg Br 76:6-12

3. Sahin V, Karakas ES, Aksu S, Atlihan D, Turk CY, Halici M (2003) Traumatic dislocation and fracture-dislocation of the hip: a long-term follow-up study. J Trauma 54:520-529

4. Philippon MJ, Kuppersmith DA, Wolff AB, Briggs KK (2009) Arthroscopic findings following traumatic hip dislocation in 14 professional athletes. Arthroscopy 25:169-174

5. Thompson VP, Epstein HC (1951) Traumatic dislocation of the hip; a survey of two hundred and four cases covering a period of twenty-one years. J Bone Joint Surg Am 33-A:746-778

6. Stewart MJ, Milford LW (1954) Fracture-dislocation of the hip; an end-result study. J Bone Joint Surg Am 36:315-342

7. Epstein HC (1973) Traumatic dislocations of the hip. Clin Orthop Relat Res:116-142

8. Erb RE, Steele JR, Nance EP Jr, Edwards JR (1995) Traumatic anterior dislocation of the hip: spectrum of plain film and CT findings. AJR Am J Roentgenol 165:1215-1219

9. Epstein HC, Harvey JP Jr (1972) Traumatic anterior dislocation of the hip, management and results - An analysis of fifty-five cases. J Bone Joint Surg Am 43-A:1561-1562

10. DeLee JC, Evans JA, Thomas J (1980) Anterior dislocation of the hip and associated femoral-head fractures. J Bone Joint Surg Am 62:960-964

11. Vailas JC, Hurwitz S, Wiesel SW (1989) Posterior acetabular fracture-dislocations: fragment size, joint capsule, and stability. J Trauma 29:1494-1496

12. Sherlock DA (1988) Traumatic anterior dislocation of the hip. J Trauma 28:411-413

13. Toms AD, Williams S, White SH (2001) Obturator dislocation of the hip. J Bone Joint Surg Br 83:113-115

14. Haddad RJ, Cook SD, Brinker MR (1990) A comparison of three varieties of noncemented porous-coated hip replacement. J Bone Joint Surg Br 72:2-8

15. Harris WH (1969) Traumatic arthritis of the hip after dislocation and acetabular fractures: treatment by mold arthroplasty. An end- result study using a new method of result evaluation. J Bone Joint Surg Am 51:737-755

16. Bellamy N, Buchanan WW, Goldsmith CH, Campbell J, Stitt LW (1988) Validation study of WOMAC: a health status instrument for measuring clinically important patient relevant outcomes to antirheumatic drug therapy in patients with osteoarthritis of the hip or knee. J Rheumatol 15:1833-1840

17. Zahiri CA, Schmalzried TP, Szuszczewicz ES, Amstutz HC (1998) Assessing activity in joint replacement patients. J Arthroplasty 13:890-895

18. Tonnis D, Heinecke A (1999) Acetabular and femoral anteversion: relationship with osteoarthritis of the hip. J Bone Joint Surg Am 81:1747-1770

19. Brooker AF, Bowerman JW, Robinson RA, Riley LH Jr (1973) Ectopic ossification following total hip replacement. Incidence and a method of classification. J Bone Joint Surg Am 55:1629-1632

20. Ficat P, Arlet J (1973) Pre-radiologic stage of femur head osteonecrosis: diagnostic and therapeutic possibilities. Rev Chir Orthop Reparatrice Appar Mot 59:Suppl:26-38

21. Baker SP, O'Neill B, Haddon W Jr, Long WB (1974) The injury severity score: a method for describing patients with multiple injuries and evaluating emergency care. J Trauma 14:187-196

22. Bastian JD, Büchler L, Meyer DC, Siebenrock KA, Keel MJ (2010) Surgical hip dislocation for osteochondral transplantation as a salvage procedure for a femoral head impaction fracture. J Orthop Trauma 24:e113-e118

23. Al-Shaikh RA, Chou LB, Mann JA, Dreeben SM, Prieskorn D (2002) Autologous osteochondral grafting for talar cartilage defects. Foot Ankle Int 23:381-389

24. Ansah P, Vogt S, Ueblacker P, Martinek V, Woertler K, Imhoff $\mathrm{AB}$ (2007) Osteochondral transplantation to treat osteochondral lesions in the elbow. J Bone Joint Surg Am 89:2188-2194

25. Hangody L, Vasarhelyi G, Hangody LR et al (2008) Autologous osteochondral grafting-technique and long-term results. Injury 39(Suppl 1):S32-S39

26. Scheibel M, Bartl C, Magosch P, Lichtenberg S, Habermeyer P (2004) Osteochondral autologous transplantation for the treatment of full-thickness articular cartilage defects of the shoulder. J Bone Joint Surg Br 86:991-997

27. Alonso JE, Volgas DA, Giordano V, Stannard JP (2000) A review of the treatment of hip dislocations associated with acetabular fractures. Clin Orthop Relat Res 377:32-43

28. Armstrong JR (1948) Traumatic dislocation of the hip joint; review of 101 dislocations. J Bone Joint Surg Am 30B:430-445

29. Tannast M, Pleus F, Bonel H, Galloway H, Siebenrock KA, Anderson SE (2010) Magnetic resonance imaging in traumatic posterior hip dislocation. J Orthop Trauma 24:723-731 